Portland State University

PDXScholar

3-1-1990

\title{
Pulse-train instabilities of a synchronously pumped mode-locked dye laser: experimental phase plots
}

Duncan Leo MacFarlane

Lee W. Casperson

Portland State University

Follow this and additional works at: https://pdxscholar.library.pdx.edu/ece_fac

Part of the Electrical and Computer Engineering Commons

Let us know how access to this document benefits you.

\section{Citation Details}

D. L. MacFarlane and Lee W. Casperson, "Pulse-train instabilities of a synchronously pumped modelocked dye laser: experimental phase plots," J. Opt. Soc. Am. B 7, 285-287 (1990).

This Article is brought to you for free and open access. It has been accepted for inclusion in Electrical and Computer Engineering Faculty Publications and Presentations by an authorized administrator of PDXScholar. Please contact us if we can make this document more accessible: pdxscholar@pdx.edu. 


\title{
Pulse-train instabilities of a synchronously pumped mode-locked dye laser: experimental phase plots
}

\author{
D. L. MacFarlane \\ Erik Jonsson School of Engineering and Computer Science, The University of Texas at Dallas, Richardson, Texas \\ 75083
}

Lee W. Casperson

Department of Electrical Engineering, Portland State University, Portland, Oregon 97207

Received August 28, 1989; accepted November 22, 1989

\begin{abstract}
We present experimental phase plots of the pulse-train instability that occurs in synchronously pumped modelocked dye lasers. From these plots we infer that the instability is of a quasi-periodic, nonlinear dynamical nature. Further, we note that the information lost in this two-dimensional representation is precisely the periodic-versuserratic character and therefore is of considerable importance.
\end{abstract}

\section{INTRODUCTION}

In a recent paper we experimentally studied the long-term (microsecond) behavior of the pulse train from a synchronously pumped mode-locked (SPML) laser and uncovered a significant modulation-both periodic and erratic-that greatly adds to the noise character of these systems. ${ }^{1}$ Since that work, similar pulse-train instability behavior in a variety of different mode-locked lasers has been reported. ${ }^{2-7}$ Consequently, this pulse-train instability is also of interest in the context of the fundamental nonlinear dynamics of lasers, and in this sphere it is important to represent the data in many different forms. ${ }^{8-10}$ Of the many ways to represent temporal trajectories, the phase plot, or attractor-for example, the $x-y$ representation of the intensity versus its derivative-is a favorite among theoreticians. ${ }^{8-11}$ In this paper we present experimental phase plots of the SPML pulse-train instability. From these plots we infer that the character of the instability is that of a quasi-periodic, nonlinear dynamical system. 9,10 In addition, we note a shortcoming of the phase plots: it is impossible to discern the specific issue of periodic modulation versus erratic modulation.

\section{EXPERIMENT}

Our Rhodamine 6G SPML dye laser is pumped by an acousto-optically mode-locked argon laser and is described in Ref. 1. The energy in each pulse is integrated by using a bandwidth-limited silicon photodiode (Antronics S-2), and this signal is processed with a fast digital oscilloscope (Tektronics DSA 602). By using the DSA 602 in this manner, it is easy to obtain the essentially real-time displays of intensity versus its computed time derivatives. The order of the derivative displayed corresponds to a rotation in phase space of the trajectory, and for this study we chose $I$ versus $\mathrm{d} I / \mathrm{d} t$. We note that this is the same as plotting $I(t+\tau)$ versus $I(t) .^{8-11}$ For the plots shown below, the signal from the photodiode is first filtered at $\sim 100 \mathrm{MHz}$. This effectively integrates over each pulse and exposes the envelope variations. The derivative of this envelope is then calculated numerically by a preprogrammed algorithm. Here, as with most digital techniques, we are faced with the compromise between record length and frequency of samples, and the examples below represent a reasonable trade-off, despite the abrupt, straight-line connections. Figure 1 is such a phase plot for the laser operating at its optimum cavity-length detuning. From the structure of this plot and that of its higher-order derivative relations, we infer that the character of the instability is quasi-periodic. On viewing the real-time data $[I(t)$ versus $t]$ and the rf spectrum data $[I(\omega)$ versus $\omega]$ taken about the first $c / 2 L$ component shown in Fig. 2 , we see that the modulation envelope is erratic.

A key experimental parameter in our studies is the cavity detuning or, equivalently, the length mismatch, between the pump laser and the dye laser. At large detunings $(>100 \mu \mathrm{m})$ the pulse-train envelope is perfectly repetitive, as shown in Fig. 3. The phase plot of the laser operating in this regime is shown in Fig. 4. We note that there is no difference between Figs. 4 and 1 that $a$ priori suggests the great difference in character between an erratic envelope and a periodic amplitude modulation. The density of orbits is more evenly distributed in the periodic case, however, and this might lead to the proper conclusion that each part of the attractor is being visited equally, continuously.

\section{CONCLUSIONS}

We have presented the experimental phase plots for a SPML dye laser operating under different regimes as dictated by the cavity-length mismatch between the pump laser and the dye laser. These plots suggest that theoretical modeling of these lasers can be undertaken by considering a periodically driven nonlinear oscillator. ${ }^{11}$ The similarity of the two phase plots taken under dramatically different operating conditions implies that phase plots are in fact of limited value in fully characterizing certain types of laser instability. 


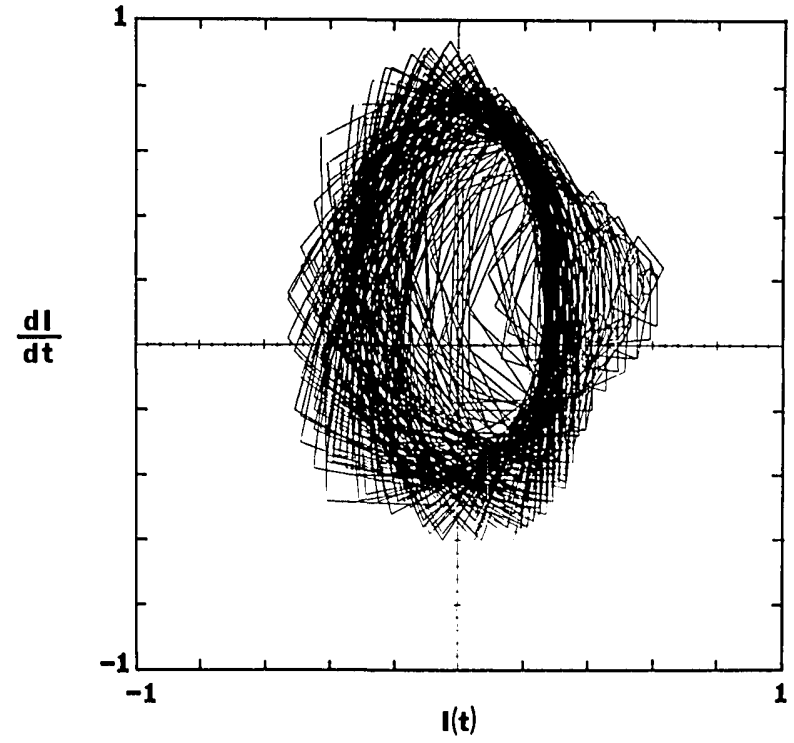

Fig. 1. Phase plot of the erratic SPML laser pulse-train instability at the optimum cavity length.

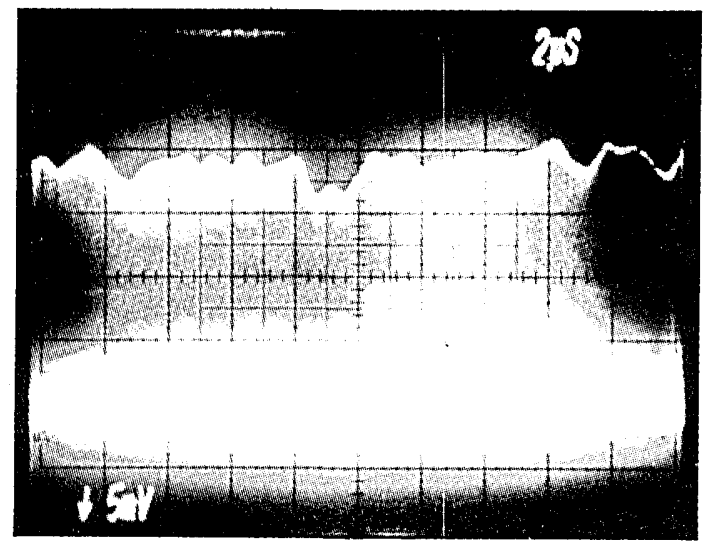

(a)

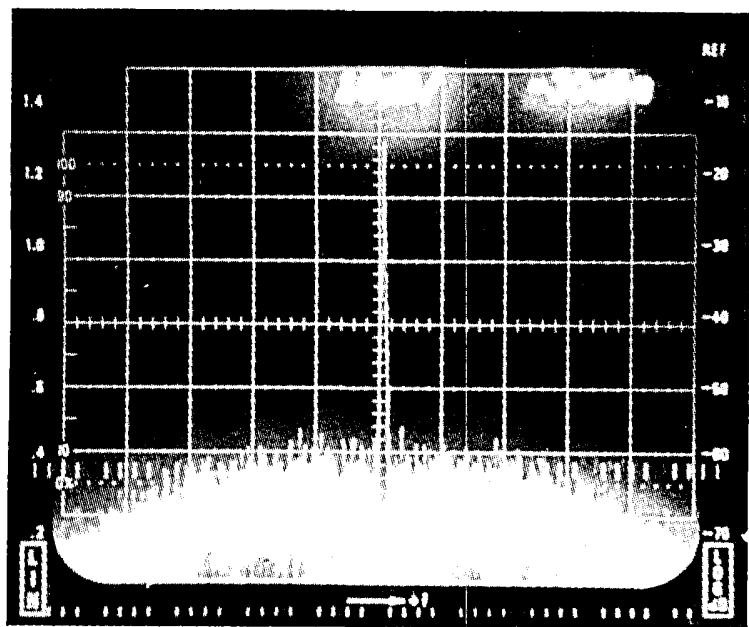

(b)

Fig. 2. (a) Temporal and (b) rf spectral data of the erratic SPML laser pulse-train instability at the optimum cavity length. The time scale in (a) is $2 \mu \mathrm{sec} /$ division; the rf homodyne spectrum is centered about $c / 2 L=80.5 \mathrm{MHz}$, and its scale is $200 \mathrm{kHz} /$ division.

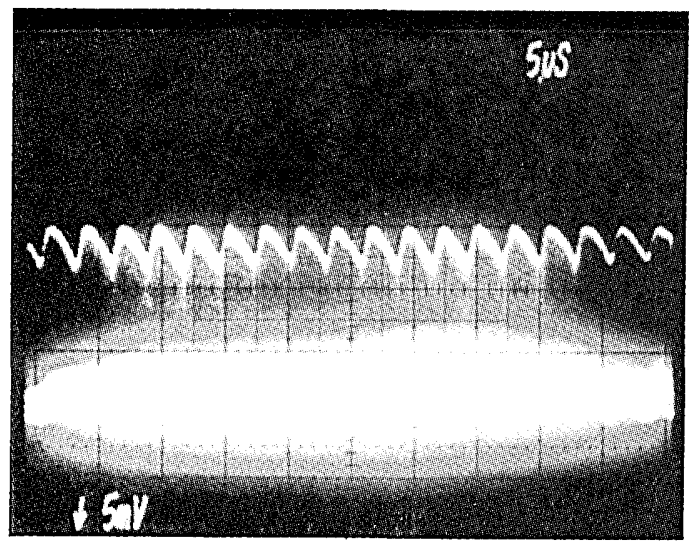

(a)

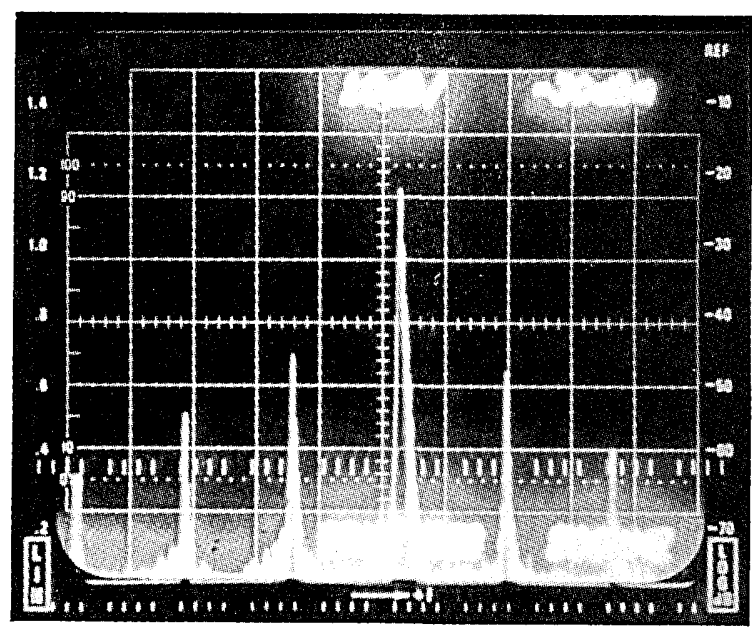

(b)

Fig. 3. (a) Temporal and (b) rf spectral data of the periodic SPML laser pulse-train instability. The time scale in (a) is $5 \mu \mathrm{sec} /$ division; the rf homodyne spectrum is centered about $c / 2 L=80.5 \mathrm{MHz}$, and its scale is $200 \mathrm{kHz} /$ division.

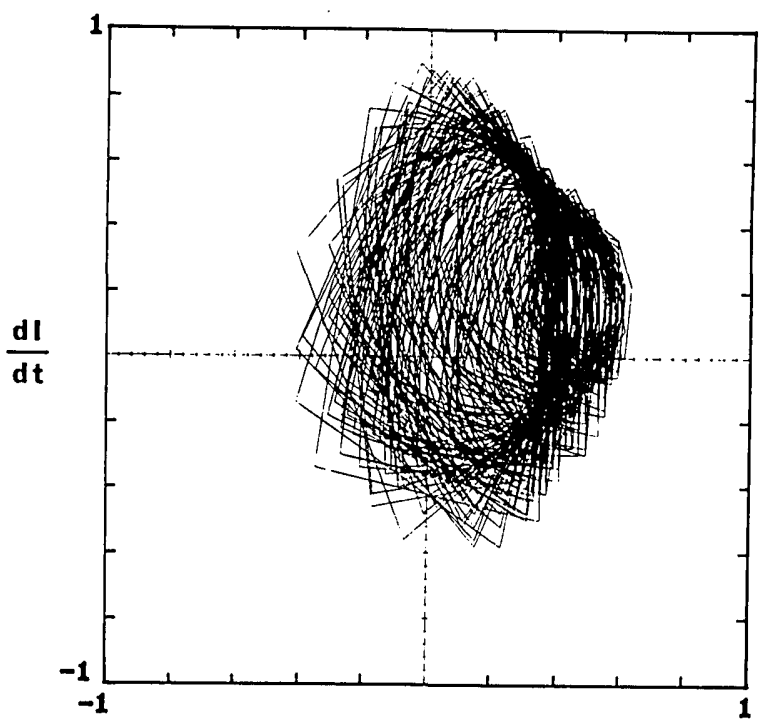

$I(t)$

Fig. 4. Phase plot of the periodic SPML laser pulse-train instability. 
If one is able to observe the cycle-to-cycle evolution of the attractor, then sometimes additional dynamic information is revealed that suggests the mode of behavior being exhibited.

An alternative method of characterizing chaotic behavior is the calculation of dimensionality. ${ }^{8-11}$ This technique requires extensive record lengths and extended computing time. Further, the interpretation and robustness of the current algorithms is still a subject of study. Nonetheless it is probable that in the future this, or a similar concept, will be a preferred technique of cataloging chaos.

\section{ACKNOWLEDGMENT}

This research was supported by the National Science Foundation under grant ECS-8511593 and by Tektronix, Inc. The authors are particularly grateful to Nellie W. Brock for her kind assistance in arranging the loan of the DSA 602.

D. L. MacFarlane is also with the Center for Applied Optics, The University of Texas at Dallas.

\section{REFERENCES}

1. D. L. MacFarlane, L. W. Casperson, and A. A. Tovar, "Spectral behavior and pulse train instabilities of a synchronously pumped mode-locked dye laser," J. Opt. Soc. Am B 5, 11441152 (1988).

2. D. L. MacFarlane and L. W. Casperson, "Pulse train instabilities in a mode-locked argon laser: experimental studies," J. Opt. Soc. Am. B 4, 1777-1780 (1987).

3. H. Avramopoulous, P. M. W. French, J. A. R. Williams, G. H. C. New, and J. R. Taylor, "Experimental and theoretical studies of complex pulse evolutions in a passively mode-locked ring dye laser," IEEE J. Quantum Electron. QE-24, 1884-1892 (1988).

4. W. L. Nighan, Jr., T. Gong, and P. M. Fauchet, "Generation and control of solitons and solitonlike pulses in a femtosecond ring dye laser," Opt. Lett. 14, 447-449 (1989).

5. W. L. Nighan, Jr., T. Gong, and P. M. Fauchet, "Solitons and related periodic pulse evolutions in a femtosecond ring dye laser," IEEE J. Quantum Electron. (to be published).

6. D. Baums, W. Elsasser, and E. O. Gobel, "Farey tree and devils staircase of a modulated external cavity semiconductor laser," Phys. Rev. Lett. 63, 155-158 (1989).

7. M. F. H. Tarroja, M. Sharafi, and L. W. Casperson, "Spontaneous mode-locking in long-cavity xenon lasers," J. Opt. Soc. Am. B 6, 1564-1573 (1989).

8. H. L. Swinney, "Observations of order and chaos in nonlinear systems," Physica 7, 3-15 (1983).

9. N. B. Abraham, J. P. Gollub, and H. L. Swinney, "Testing nonlinear dynamics," Physica 11D, 252-264 (1984).

10. J.-P. Eckmann and D. Ruelle, "Ergodic theory of chaos and strange attractors," Rev. Mod. Phys. 57, 617-656 (1985).

11. T. Ogawa, E. Ogawa, and E. Hanamura, "Numerical analysis of a multi-mode laser with modulated inversion," Appl. Phys. B 43, 139-153 (1987). 